\title{
CONFLICTOS RELIGIOSOS Y ADHESIONES POLÍTICAS EN LA GUERRA REVOLUCIONARIA. LA RETIRADA DEL EJÉRCITO AUXILIAR DEL PERÚ EN 1811*
}

\author{
Religious conflicts and political adhesions in the revolutionary war. The \\ retirement of the auxiliary army of Peru in 1811
}

Fernando D. Gómez**

\begin{abstract}
Resumen
La guerra revolucionaria que siguió a la generación de la junta de gobierno de Buenos Aires en 1810 enfrentó a ejércitos cuyas identificaciones no pueden asociarse a los posteriores marcos nacionales. Estos ejércitos apelaron a diversos dispositivos a la hora de generar adhesiones. En este trabajo abordamos esta problemática considerando a la dimensión religiosa como un pilar fundamental en la inscripción que los líderes intentaron delinear para sus ejércitos pero también en la construcción simbólica de los enemigos. Sin embargo, entendemos que las implicancias de esas acciones y la repercusión que tuvieron no pueden analizarse sin contemplar el desempeño global de los ejércitos, principalmente en cuanto a su relación con las comunidades locales. Estos planteos se nutren de fuentes provenientes de memorias de partícipes, causas judiciales, autos, bandos, proclamas y otros registros en algunos casos editados y en otros sitos en archivos de Buenos Aires y de Sucre.
\end{abstract}

$<$ Guerra revolucionaria $><$ Dimensión religiosa $><$ Adhesión política $><$ Saqueos $>$

\begin{abstract}
The revolutionary war that followed the creation of the junta de gobierno of Buenos Aires in 1810 confronted armies whose identities cannot be associated to the later national boundaries. These armies appealed to diverse devices in order to generate support. This article deals with this topic considering the religious dimension as a fundamental foundation in the identification the leaders of these armies built for their armies, but also in the symbolic construction of the enemies. Nevertheless, we understand that the implications of those actions and the repercussion of them cannot be analyzed without studying the global performance of the armies, mainly in its relationship with the local communities. These hypothesis nourished from memories of that period, judicial causes, proclamations and other published and unpublished records located in archives of Buenos Aires and Sucre.
\end{abstract}

$<$ Revolutionary war $><$ Religious dimension $><$ Political support $><$ Sackings $>$

Recibido: 10/11/2014 // Aceptado: 04/06/2015

\footnotetext{
* Un avance de este trabajo fue presentado en las Jornadas Interescuelas realizadas en Mendoza en 2013 por lo que agradezco a Nancy Calvo los sugerentes comentarios realizados en ese momento. Agradezco también los comentarios de María Elena Barral, Valentina Ayrolo, Laura Mazzoni, Lucas Rebagliati, Tomás Guzmán y Bárbara Caletti. Han sido muy útiles las indicaciones de quienes cumplieron la labor de referato de este trabajo, por lo que les agradezco su lectura.

** Licenciado en Historia, UBA-Conicet. fedagofe@hotmail.com
} 
Gómez. Conflictos religiosos y adhesiones políticas en la guerra revolucionaria. La retirada del ejército...

La Revolución de Mayo de 1810 dio comienzo en el Río de la Plata a una etapa que estuvo signada por la guerra en diversos puntos del territorio. Desde Buenos Aires partieron ejércitos con el objetivo de lograr la adhesión a la causa revolucionaria en distintos frentes del espacio político que comprendía el Virreinato del Río de la Plata (Morea, 2011). Dichos ejércitos estuvieron conformados a partir de los batallones de milicias que se habían creado luego de la invasión británica sobre Buenos Aires producida en 1806 (Halperin Donghi, 1978).

Sin dudas, en un primer momento el más importante de esos frentes lo constituyó el Alto Perú, donde se encontraba la fuente de ingresos más significativa de la época, como era la producción mineral de plata. Hacia ese destino partió desde Buenos Aires el Ejército Auxiliar del Perú a mediados de 1810. En diciembre del mismo año, dicho ejército había logrado controlar el Alto Perú, ocupar la ciudad clave de Chuquisaca e intervenir en Potosí. Sin embargo, este control sería efímero ya que pocos meses después, el 20 de junio de 1811, las tropas enviadas desde Lima y dirigidas por Juan Manuel de Goyeneche derrotaron al ejército remitido desde Buenos Aires y sus aliados en las inmediaciones del río Desaguadero. En adelante, el Alto Perú se tornó en un territorio complejo e indefinido, con predominancia del control limeño pero también con ciertos focos de guerrillas que se identificaban con la causa revolucionaria. Las dificultades políticas y militares que tenían los ejércitos para imponerse se debieron a múltiples causas, desde la escabrosa geografía de la zona hasta la tradición política de las comunidades locales, pasando por el propio comportamiento de las tropas y la oficialidad de los ejércitos. A fin de cuentas, el plan continental que ideó unos años después José de San Martín para intervenir sobre Lima, la capital del Virreinato del Perú, buscó evitar el paso por tierras altoperuanas.

En este trabajo nos proponemos indagar en las adhesiones-político militares que generaron los ejércitos. Dichas adhesiones cobran especial relevancia si advertimos que buena parte de los resultados bélicos parecen estar ligados en forma estrecha con las relaciones que los ejércitos desarrollaron con las comunidades locales en la medida que dependían de ellas para abastecerse de recursos pero también de hombres que sumasen sus voluntades a la guerra. Por otro lado las adhesiones políticas se tornaron trascendentes para aminorar un problema tan grave como recurrente como era la deserción de la tropa (Rabinovich, 2011 y 2013). En trabajos previos consideramos la relevancia de la dimensión religiosa como espacio de interpelación por parte de los líderes en la construcción de idearios comunes (Gómez, 2011 y 2013). En este artículo nos preguntamos acerca de las implicancias de dichas interpelaciones. El interrogante que guía la investigación aquí desarrollada sería entonces: ¿constituía el plano religioso la más significativa dimensión dentro de las creencias de la época a la hora de referenciarse y referenciar negativamente a los adversarios? ${ }^{1}$

\footnotetext{
1 Repetidas veces en este trabajo se hace mención a las creencias de las comunidades locales. Es importante aclarar que el concepto de creencias tiene una tradición analítica y se encuentra en boga en otras latitudes. En este trabajo no avanzamos en una definición precisa del mismo pero si nos interesa resaltar dos aspectos que nos llevan a utilizarlo: en primer lugar la potencialidad que supone para pensar los actos de creer como experiencias colectivas en tanto presuponen una referenciación que trasciende lo individual
} 
Resulta de vital trascendencia, en el marco de guerra que nos ocupa, el nombramiento que el General Manuel Belgrano realizó al nominar a la Virgen de la Merced como Generala del ejército una vez obtenido el triunfo en la batalla de Tucumán. Este nombramiento ha sido estudiado como parte de la trama religiosa de la guerra en el Alto Perú, ubicándolo como una respuesta al accionar de Goyeneche, quien habría aprovechado ciertos descuidos de Castelli en términos religiosos (Ortemberg, 2012). En este trabajo nos detenemos en la retirada hacia el sur del Ejército Auxiliar del Perú una vez consumada la derrota en la batalla del Desaguadero. El análisis de esta retirada no solo nos puede indicar ciertas claves sobre el nombramiento de Belgrano sino que además puede ser un eslabón válido para intentar comprender los problemas posteriores que tendrían los nuevos intentos de conquistar el Alto Perú para la causa revolucionaria. Prestaremos especial atención a la dimensión religiosa sin dejar de resituarla en su compleja coyuntura, para ello utilizamos fuentes de testigos de la época, documentación del Archivo General de la Nación sito en Buenos Aires, del Archivo Nacional de Bolivia y del Archivo Arquidiocesano "Monseñor Miguel de los Santos Taborga", los dos últimos ubicados en Sucre.

El trabajo se divide en tres partes y una conclusión. En la primera parte intentamos ubicar nuestra hipótesis y el problema aquí abordado en el marco historiográfico actual. En la segunda parte ponderamos la actuación de la primera expedición al Alto Perú en lo concerniente a la dimensión religiosa y en la tercera indagamos en las acusaciones que se dieron sobre el ejército en retirada. Finalmente, en las conclusiones recuperamos el interrogante central para intentar una respuesta a partir de las evidencias revisadas.

\section{La guerra revolucionaria}

Antes de comenzar a indagar en la retirada del Ejército Auxiliar del Perú, nos parece oportuno considerar someramente las formas de hacer la guerra vigentes en este período y las identidades en pugna que delimitaban los sentidos de pertenencia a un bando u otro. Estos tópicos serán relevantes para comprender las implicancias de la dimensión religiosa en las disputas bélicas y políticas. La historiografía tradicional ha estudiado las guerras que siguieron a la Revolución de Mayo demarcando una línea divisoria entre "guerras de independencia" y "guerras civiles". Estos calificativos y sobre todo la consiguiente derivación lógica que suponen para comprender la pertenencia o fidelidad de los participantes, han demostrado ser improductivos para analizar

\footnotetext{
y cobra sentido en comunidad. En segundo lugar el concepto permite dar cuenta de un imaginario donde lo sacro y lo profano se entremezclan en la medida que no se piensan como diferenciados. La tradición analítica que mencionamos reconoce sus inicios en los trabajos clásicos -de principios de siglo XX-sobre sociología de la religión. Se puede ver una crítica y reelaboración de la problemática unas décadas más tarde y desde distintos ángulos en autores como Pierre Bourdieu, Michel de Certeau y -más recientementeRoger Chartier. (Bourdieu, 2009; Certeau, 2004 y 2006; Chartier, 1992). En la actualidad son sugerentes entre otros los análisis de Marie Danielle Demélas-Bohy, Marlène Albert-Llorca y Elisabeth Claverie (Demélas-Bohy, 1995; Albert-Llorca, 2005; Claverie, 2007; Claverie y Charuty, 2009). En nuestro país, el concepto ha sido utilizado con mayor aceptación en trabajos efectuados por sociólogos que estudian las prácticas religiosas (Mallimaci, 2013).
} 
Gómez. Conflictos religiosos y adhesiones políticas en la guerra revolucionaria. La retirada del ejército...

numerosas circunstancias que marcaron adscripciones a una $\mathrm{u}$ otra parcialidad. Para superar los problemas que suponen dichas nominaciones, Raúl Fradkin ha propuesto el concepto de "guerras de la revolución" señalando que "supusieron una movilización de hombres y recursos como nunca antes se había producido" de modo tal que se trato entonces de "una experiencia social de masas de máxima intensidad" (Fradkin, 2009: 1; Fradkin, 2010). Esta nueva concepción se muestra más pertinente para nuestro análisis específico, sobre todo en la etapa inicial del conflicto, cuando, por momentos, la indiferenciación de rivales parece estar a la orden del día en la cotidianeidad de las comunidades altoperuanas.

En términos más amplios, esta nueva manera de entender las guerras que se desataron en la primera mitad del siglo XIX converge con una trascendente renovación de la historiografía del período que se observa en las últimas décadas en los diferentes ámbitos de estudio de los procesos de independencia en Hispanoamérica. ${ }^{2}$ A pesar de las diferencias y los marcados matices, podemos encontrar como tópico en común de los diferentes estudios el quiebre con el marco nacional delimitado por las historiografías decimonónicas y la pretensión de comprender los distintos procesos despojándose de una mirada esencialista sobre la formación de las diversas unidades políticas. ${ }^{3}$ Los resultados más relevantes de estas investigaciones, nos permiten hablar de cierto consenso historiográfico que resitúa las primeras etapas de la guerra revolucionaria como un período signado por la búsqueda de autonomía, no solamente de las grandes jurisdicciones sino de cada uno de "los pueblos" que conformaban la monarquía española. Como lo han destacado distintos investigadores, los interrogantes que surgen a partir de dicho consenso son numerosos. Para comenzar a pensar en nuestra problemática puntual, hay que destacar que en el estudio de la conformación de las identidades y los sentidos de pertenencia posrevolucionarios se debe tener en cuenta la dificultad de proyectar una vinculación común entre espacios territoriales que se pretenden autónomos.

El análisis de la dimensión religiosa cobra entonces relevancia al reponer uno de los recurrentes dispositivos que permitieron delimitar marcos identitarios comunes, debido al gran involucramiento que generaba en una sociedad piadosa que contenía un frondoso espacio de prácticas y creencias religiosas. ${ }^{4} \mathrm{La}$ historiografía local ha comenzado a entrever esta dimensión en este sentido con algunos resultados notables pero aún incipientes en el marco de las guerras de la revolución. ${ }^{5}$ Sin embargo, en otras

2 Dada la envergadura y cantidad de análisis al respecto, remitimos a dos estados de la cuestión: el primero, cuando esta renovación cobraba fuerza y el segundo, más reciente, cuando ya se haya ciertamente extendida. De este modo, la traza temporal prefigura asimismo las variaciones. (Halperin Donghi, 1986), (Ávila, 2004).

3 En esta dirección se inscriben numerosas investigaciones destacándose en nuestro país las iniciadas por José Carlos Chiaramonte. (Chiaramonte, 1991 y 1997).

${ }^{4}$ Cabe remarcar, siguiendo los estudios de Jaime Peire y de Roberto Di Stefano, que no se puede concebir una esfera religiosa autónoma para la época. (Peire, 2000; Di Stefano y Zanatta, 2000; Di Stefano, 2004).

5 El análisis más destacado en este sentido es (Ortemberg, 2012) y (Ortemberg y Sobrevilla Perea, 2011). Asimismo María Elena Barral reafirma la importancia de este tipo de estudios puesto que los protagonistas de las guerras de independencia "insistían en la dimensión religiosa de su empresa" (Barral, 2007). Para un estado de la cuestión sobre la historiografía local sobre la guerra véase (Di Meglio, 2007). 
latitudes encontramos trabajos de estas características, destacándose los avances de Marie-Danielle Demelas-Bohy para la zona de los Andes (desde Ecuador hasta el Alto Perú), donde advierte que "la guerra de independencia puede presentarse como una guerra religiosa porque el discurso de legitimación de la guerra es religioso, proveniente de las enseñanzas de la Iglesia y forjado por ella" (Demelas-Bohy, 1995: 162). Desde otra perspectiva analítica, resaltando en el proceso revolucionario atlántico una matriz "conservadora de los pilares de la constitución política tradicional", Annick Lempérière ha señalado que "la cultura de la guerra fue ante todo una cultura religiosa (...) la religión era la que confería a las luchas su sentido último y su legitimidad más obvia" (Lempérière, 2004: 35). Finalmente nos parece interesante mencionar el trabajo de Genís Barnosell, en la medida que, analizando el sitio de Zaragoza y Gerona -en el marco de la ocupación francesa de la península en 1808-, advierte que no se trata de resaltar la presencia de la religión, sino de entender el lugar que dicha dimensión ocupa en la lógica bélica en general (Barnosell, 2010).

De este modo, retomando al último autor, parece necesario considerar el lugar específico que ocupa la religión en cada uno de los múltiples pliegues de la guerra revolucionaria en la medida que las acusaciones de herejía o impiedad se repiten en uno y otro grupo tanto como la sacralización de la propia causa. Justamente por esto es que se torna imprescindible el esfuerzo por intentar recuperar las recepciones que tienen dichas acusaciones y, en la medida de lo posible, dar un paso más adelante tratando de explicar las implicancias de dichas recepciones.

Como mencionamos, no hay una frondosa historiografía local sobre estas preocupaciones. Sin embargo no se trata de un campo yermo y sí encontramos diversos trabajos con los que dialogaremos a lo largo del artículo. Así, el caso que aquí nos ocupa ha sido tratado en diversas obras generales sobre la historia de la iglesia en la región. A pesar de sus puntos de partida confesionales, Cayetano Bruno ha tratado la primera expedición al Alto Perú en forma rigurosa en cuanto a la utilización de fuentes, por lo que se vuelve una obra de referencia indiscutida (Bruno, 1954, 1972 y 1992). Entre los trabajos más recientes encontramos que Roberto Di Stefano trabajó la temática brevemente en dos libros de síntesis (Di Stefano, 2010; Di Stefano y Zanatta, 2010). Por otro lado, se puede delimitar una corriente de estudios que se ha abocado al estudio de los sermones como mecanismo de interpelación política (Martínez de Sánchez y Clissa, 2010). ${ }^{6}$

Más cercanos a nuestro objeto de estudio, se destacan además dos estudios tradicionales y dos trabajos específicos sobre la dimensión religiosa. Entre los tradicionales, la segunda parte del libro de Edberto Acevedo cobra relevancia por la notable cantidad de información que reúne (Acevedo, 1992). En segundo lugar, podemos mencionar un trabajo pionero de Jorge María Ramallo (Ramallo, 1966) que contiene algunos problemas debido a la falta de citas probatorias en algunas afirmaciones

\footnotetext{
${ }^{6}$ La bibliografía sobre los sermones en este período es bastante amplia y se ha focalizado en la mediación cultural que suponen. Se han realizado estudios sobre un caso concreto y sobre un período más extenso (Herrero, 2012; Ayrolo, 2009).
} 
Gómez. Conflictos religiosos y adhesiones políticas en la guerra revolucionaria. La retirada del ejército...

trascendentes y al seguimiento de la obra de Bernardo Frías Historia del General Martín Miguel de Güemes y de la Provincia de Salta o sea de la Independencia Argentina (Frías, 1971). ${ }^{7}$

Para finalizar este apartado, encontramos un primer trabajo específico que suma interpretaciones que enriquecen este artículo y plantea problemáticas con las que dialogaremos. Nos referimos al reciente artículo de Pablo Ortemberg que pone especial énfasis en los rituales y en las figuras de las vírgenes pero que trata con minuciosidad la coyuntura histórica que abordamos. ${ }^{8}$ En segundo lugar, encontramos una compilación reciente que contiene trabajos que abordan distintas regiones para indagar en la relación entre la política y la religión en el periodo revolucionario en América hispana. Los editores son Josep Ignasi Saranyana y Juan Bosco Carredano. Esta último abre el libro con un capítulo introductorio sumamente sugerente en el que realiza un recorrido historiográfico y señala que una de las últimas novedades "radica en el redescubrimiento de la importancia de las creencias religiosas como fundamento de las concepciones políticas básicas de la mayoría del pueblo" (Amores Carredano, 2011a: 13).

\section{Religión y política en la avanzada hacia el Alto Perú}

La religiosidad de los ejércitos formaba parte de las consideraciones que las autoridades buscaban cuidar y sostener en las campañas. Para ello se nombraban capellanes que acompañaban las expediciones. ${ }^{9}$ En el caso del Ejército Auxiliar del Perú, en un principio, el nombramiento recayó en dos miembros del clero secular: como primer capellán Juan Ruiz y como segundo Manuel Albariño. ${ }^{10}$ Sin embargo, ninguno de los dos asumiría el puesto asignado y los reemplazantes serían dos clérigos de la Orden de la Merced. ${ }^{11}$ Finalmente a fines de junio de 1810 quedaron entonces como primer

\footnotetext{
Frías era apegado a cierta prácticas históricas en las que las fuentes son meramente un punto de partida para dejar volar la pluma de su intérprete de forma tal que no deja de ser problemática la utilización de Frías sin comprobar con detenimiento sus aseveraciones. La obra de este autor data de principios de siglo XX, y sigue una práctica de hacer historia instituida por Vicente López. Los pasajes literarios más interesantes de Frías se encuentran en la descripción de ciertos líderes en los que deja entrever sus prejuicios con mayor nitidez que lo que quiere describir. Véase en este sentido la descripción de Castelli (Frías, 1971: 131).

8 Otro trabajo sobre el tema corresponde a un capítulo de un reciente libro generado por el Grupo de Trabajo de Historia Militar de la Academia Nacional de la Historia. Dicho capítulo conforma una síntesis de la presencia religiosa en los ejércitos con eje en los líderes y sin adentrarse en las prácticas o la religiosidad de las tropas (Picciuolo, 2013).

9 Los capellanes castrenses tenían jurisdicción sobre los militares de la expedición en actividad. El nombramiento estaba en un principio en manos del Rey pero luego fue delegado a Tenientes Vicarios. Al momento de la Revolución, el Obispo de Buenos Aires, Benito Lué y Riega, era el Teniente Vicario General del Ejército en actividad para el Río de la Plata y como tal fue el encargado de aprobar los nombramientos sugeridos por la Junta de gobierno. (García de Loydi, 1965: T I 14 y ss).

${ }^{10}$ Ambos nombramientos son del 14 de junio. Para Ruiz véase Archivo General de la Nación (AGN), Sala X, Legajo 2-4-9, folio 235. Para Albariño AGN, X-2-4-9. f. 234. Erróneamente Ruiz aparece con el nombre de pila Joaquín y en otras menciones encontramos a Albariño como Alvariño.

${ }^{11}$ En primer lugar se exoneró a Ruiz debido a sus tareas docentes quedando Albariño como primer capellán. Luego el Obispo Lué no aprobó a Albariño en los exámenes necesarios bajándolo de su cargo. La exoneración de Ruiz se produjo el 18 de junio, en AGN, X-2-4-9. f. 250. El nombramiento de primer
} 
capellán Manuel Ascurra y como segundo Antonio de la Cuesta: ${ }^{12}$ de todos modos no irían solamente clérigos mercedarios puesto que se sumó a ellos el dominico Justo Ponce de León. ${ }^{13}$ Asimismo es importante recalcar que el nombramiento de mercedarios no era extraño puesto que, por la tradicional característica de la Orden, participaban habitualmente en expediciones: hubo mercedarios acompañando a la tropa veterana que se envío en 1781 para reprimir el levantamiento de Túpac Amaru como así también asistieron piadosamente a las expediciones a las salinas. ${ }^{14}$

Por otro lado hay que considerar que desde los sucesos de mayo de 1810 la Junta había encontrado como aliados a buena parte de los mercedarios de Buenos Aires: el 22 de mayo, en el Cabildo Abierto, Hilario Torres y Juan Manuel Aparicio, Provincial y Comendador de la Orden respectivamente, votaron a favor del nuevo gobierno, y el 25 de mayo ambos, junto a un grupo de clérigos de la Orden, firmaron una hoja en apoyo de la nueva Junta con la siguiente rúbrica "En virtud y accediendo a la representación de comandantes y vecindario de esta capital, prestamos nuestra suscripción" ${ }^{15}$ En esta misma línea de apoyo, Hilario Torres contestó a la Junta, ante el anuncio del nombramiento de Ascurra como capellán, de la siguiente manera: "...no solo me halla V. E. obsecuente al expresado nombramiento de dicho padre, sino también deseando ser útil en la parte que pueda caber me pongo a la disposición de V. E. desde ahora todo el departamento de mi Provincia para que de cualquier Convento de ella en que tocase la expedición pueda levantar los otros Religiosos que considere útiles a tan importante objeto". ${ }^{16}$

capellán de Albariño, también el 18 de junio en AGN, X-2-4-9. f. 249. La resolución de Lué, el 30 de junio, en AGN, X-2-4-9. fs. 269-70. Es posible que la reticencia del clero secular a ocupar el puesto de capellán se deba a las potenciales carreras personales dentro del obispado de Buenos Aires. De todos modos, el puesto de Capellán del Ejército no parece ser despreciable para todos los clérigos si tenemos en cuenta peticiones como la de Fray Martín Rodríguez, cuando se dirige a la Junta de gobierno el 6 de julio de 1810 y "solicita se le confiera nombramiento a Capellán de los cuerpos que se elevan a regimiento". AGN, X-2-2-3, f. 166.

${ }^{12}$ Ascurra figura también como Escurra, Ascorra o Azcorra. AGN, X-2-2-3. f. 171. AGN, X-2-4-9. fs. 2456. En el nombramiento de la Junta se menciona: las bellas circunstancias, literatura y demás cualidades que concurren en dicho Manuel lo hacen acreedor a esta confianza. AGN, X-2-4-9. f. 248.

${ }^{13}$ AGN, X-2-2-3. fs. 248-9.

${ }^{14}$ El clérigo Pedro Ignacio Morales fue el capellán enviado al Alto Perú en 1781 (Brunet, 1974: 28). Por otro lado, además de nombramientos para los fuertes y fortines encontramos, por ejemplo, la designación de José Castro como Capellán para la Expedición de Salinas el 19 de setiembre de 1810 y luego, ante la baja de Castro, un nuevo pedido al provincial mercedario para que provea reemplazante, siendo nombrado Gregorio Maldonado, dos días más tarde, para acompañar la expedición comandada por Pedro Andrés García. Para el nombramiento de Castro, AGN, X-2-2-3. f. 186; para el de Maldonado, AGN, X-2-2-3. f. 191.

${ }^{15}$ Petitorio Popular 25-05-1810. Área Archivo Histórico, Museo Histórico Nacional. Edición facsimilar en (Carman y Álvarez Rodríguez, 2010). El historiador de la orden Euxodio Palacio señala que "otros frailes del mismo convento no alcanzaron a firmar por la urgencia del caso" y que el Padre Ascurra firmó en otra foja. Sin embargo no encontramos la rúbrica de este último en los documentos (Palacio, 1967: 12). Todas las citas textuales han sido actualizadas en términos ortográficos.

${ }^{16}$ AGN, X-2-2-3. f. 172. Unos meses más tarde Torres se distanciaría de Aparicio y solicitaría el apoyo de la Junta para que intervenga en su favor pero la respuesta no le fue favorable. AGN, X-2-2-3. f. 196 y fs. $210-15$. 
Gómez. Conflictos religiosos y adhesiones políticas en la guerra revolucionaria. La retirada del ejército...

Volviendo a la participación de los capellanes en esta primera expedición al Alto Perú, vemos que en la ciudad de Córdoba, donde el ejército encontró la primera adversidad, tuvieron que confesar a los opositores capturados que posteriormente fueron fusilados. Encontramos un relato anónimo de lo sucedido, aunque notoriamente a favor de las posiciones seguidas por las autoridades cordobesas. Fechado unos meses más tarde, cuando el fracaso de la primera expedición ya era conocido, el relato señala que Castelli negó la posibilidad de elegir confesor a los prisioneros determinando los capellanes que lo acompañaban en el ejército fuesen los encargados de confesarlos. El mismo relato remarca que los frailes mercedarios que hicieron de confesores "escandalizaron a todos los pueblos donde han estado por sus vicios y desórdenes". Atendiendo a estas conductas y avanzando sobre las del líder del ejército, el anónimo afirma: "siendo la irreligión su principal distingo, sin duda quiso Castelli que le revelasen las confesiones, y no se puede dudar lo hiciesen". ${ }^{17}$

Una vez en el Alto Perú, los capellanes se involucraron en las controversias que se gestaban al interior del ejército replicando la división que marcaba el pulso de la política en Buenos Aires. Virginia Macchi ha analizado las disputas suscitadas considerándolas como inherentes a la nueva forma de hacer la guerra, en la que los ejércitos conformaban un cabal espacio de politización (Macchi, 2012). Esta politización comprendía un terreno nuevo en cuanto a la magnitud que representaba y los eclesiásticos estaban incursionando en la misma medida que los oficiales. A fin de cuentas este involucramiento no fue beneficioso para el estricto desarrollo de sus ministerios puesto que se vieron afectados ante la agudización de las divisiones. De este modo, en la causa abierta en Buenos Aires luego de la derrota de Huaqui, encontramos declaraciones como la de Juan Madera, quien señala que estando en Oruro, en marzo de 1811, oyó al padre Ascurra “...dando gracias a Dios por la separación del doctor Moreno, y como asegurando su muerte en los términos siguientes: ya está embarcado y va a morir ..." ${ }^{18}$ El propio Ascurra volvería a aparecer en repetidas declaraciones de dicha causa indicado como el organizador de una junta de varios oficiales con los fines de "prender al doctor Juan José Castelli y al general Balcarce" para enviarlos a Buenos Aires. ${ }^{19}$ Asimismo, después de la derrota de Huaqui, Antonio González Balcarce manda una misiva al gobierno donde, entre otras cosas, advierte que Ascurra "influye a la fuga de la tropa, y así convendría separarle de ella y hacerle regresar". ${ }^{20}$ Finalmente en

\footnotetext{
${ }^{17}$ Anónimo "Relación de los últimos hechos del General Liniers", Montevideo 15 de enero de 1812, en Biblioteca de Mayo, Senado de la Nación, Buenos Aires, 1962. Tomo V, "Diarios y Crónicas", pp. 43767. Es de notar que el encono con los capellanes no se cifra en su pertenencia a la Orden de la Merced ya que el capellán que acompaña a Liniers en su retirada, Gregorio Tadeo Llanos, era también mercedario. Ídem. pp. 4356/7.

${ }^{18}$ Declaración del testigo Juan Madera, Buenos Aires, 19 de julio de 1813. En "Causa del Desaguadero", Biblioteca de Mayo, ob. cit. Tomo XIII, "Sumarios y Expediciones" 11875.

${ }^{19}$ La cita es de la declaración del médico de la expedición, Diego Parossien, Buenos Aires 23 junio de 1812, en Ídem, pp. 11626-8. El testigo Juan Antonio Argerich, en declaración de 29 de febrero de 1812 acusa a Ascurra de ser agente de Juan José Viamonte. En Ídem. p. 11801. Seguramente no está pensando en esta actuación de Ascurra el Presbítero Carlos Ruiz Santana cuando en un trabajo publicado en 1941 señala que Ascurra se distinguió "en el desempeño de sus funciones" (Ruiz Santana, 1941: 17).

${ }^{20}$ Gaceta Extraordinaria de Buenos Aires, lunes 22 de julio 1811. Citado en García de Loydi, Ludovico,
} 
noviembre de 1811, Juan Martín de Pueyrredón retiraría del ejército a los capellanes Ascurra y Cuesta enviándolos para que "se restituyan al Convento de N. Señora de las Mercedes de la Capital". ${ }^{21}$ Otra versión, indicada por el oficial José Bolaños, señalaba que Ascurra había pedido permiso "para retirarse de su ministerio por los escándalos que experimentaban los oficiales del ejército de cuyos excesos había dado parte y que no se atendía a sus exposiciones". ${ }^{22}$ De este modo, la reconstrucción de la actuación del capellán se vuelve compleja y contradictoria pero sin duda influyente en la medida que tanto quienes lo acusan como el último testimonio dan cuenta de percibir las acciones de los eclesiásticos en el marco de los conflictos internos del ejército.

Con la retirada del capellán, el ejército quedó con menor presencia de religiosos. El propio Pueyrredón se mostraba preocupado al respecto dando cuenta del vital papel que atribuía a los ausentes. Así, en una misiva a la Junta de gobierno manifestaba intranquilidad por la escasa respuesta que tenía en "la propagación del espíritu de libertad y adhesión" a la causa, advirtiendo como determinante la escasez de eclesiásticos: "son infinitos los arbitrios que invento cada día para extender y fomentar estas ideas, contando apenas con uno u otro cura". ${ }^{23}$

La presencia de los eclesiásticos nos lleva a ubicar como excedidas las imágenes que proyectan una indiferencia en el plano religioso sobre la primera avanzada hacia el Alto Perú. Más aún, saliendo de las problemáticas internas del ejército, encontramos que el apoyo de numerosos curas locales se hizo presente en la avanzada hacia al norte en el Alto Perú. ${ }^{24}$ Revisando los legajos criminales generados luego de la batalla de Huaqui encontramos imputaciones de sedición, infidencia y colaboración con el enemigo que recaen sobre los eclesiásticos que apoyaron la incursión porteña pero también a los líderes intermedios o caudillos locales insurgentes. Tal es el caso de José Hermenegildo Quiroga, cura de la doctrina del Paredón, imputado por "delito de infidencia” por haber

ob. cit. p. 75. Un tiempo después, en 1815, Ascurra lograría que la misma gaceta publique un decreto "reparador" rectificando los dichos de Balcarce 4 años antes. Ibídem.

${ }^{21}$ AGN X-3-5-7, Oficio de Pueyrredón del 17 de noviembre de 1811.

${ }^{22}$ Declaración del testigo José Bolaños, Mendoza, 2 de abril de 1812. En "Causa del Desaguadero", ob. cit. p. 11828.

${ }^{23}$ Comunicación al Gobierno. Cuartel general de Jujuy, $1^{\circ}$ de enero de 1811. En Museo Mitre, Documentos del archivo de Belgrano, Imprenta de Coni, Buenos Aires, 1913, tomo IV, p. 51.

${ }^{24}$ Esto mismo fue planteado por Frías, aunque con los problemas que ya advertimos. Así, señala que pueblos enteros de indígenas "caían de hinojos ante el representante de la Junta como muestra de su más expresiva cortesía, juntas las manos y alzados al cielo los ojos para bendecirlo; e invocando al representante de Tatay!, en su lengua quichua, que es como quien dijera ¡Señor y Padre mío!" Luego se pregunta “QQuién movía así a aquellos pueblos que el representante de la Junta creía impulsados por una mano invisible que no acertaba a descubrir? Era la misma revolución con, cuyo genio había iluminado al pueblo; la revolución popular, no militar; eran aquellos tribunos ignorados, esos agentes desconocidos y voluntarios, aquellos curas perdidos en el fondo de los valles que habían santificado ya la causa y movían ahora por ella las poblaciones en masa" (Frías, 1971: 97-98). Ramallo, toma de Frías este párrafo, pero lo glosa señalando que los indígenas "En su lengua vernácula exclamaban: ¡Tatay!, como si fuera un enviado de Dios" (Ramallo, 1966: 301) Si bien ninguno incorpora en su relato la fuente de la que toman esas expresiones, entendemos que en lugar de "tatay" se refirieron a "taita", puesto que "tatay", según la Real Academia Española, se utiliza en quechua norteño "para expresar asco o disgusto". Véase http:// buscon.rae.es/drae/srv/search?val=tatay. 
Gómez. Conflictos religiosos y adhesiones políticas en la guerra revolucionaria. La retirada del ejército...

"tomado parte activa en sostener el sistema revolucionario, y promover las inquinas ideas del principal rebelde caudillo Esteban Arce". ${ }^{25}$ Por su parte, el fraile mercedario Juan de Dias Orozco, Teniente de Cura de la Doctrina de Caracollo, fue acusado de colaborar con los caudillos insurgentes de Mohosa y en su defensa dijo que conocía al líder Monroy pero no dudó en sostener que se opuso al reclutamiento de indios. ${ }^{26} \mathrm{En}$ algunos casos las sentencias eran positivas para los eclesiásticos, como sucedió con el presbítero José Andrés Salvatierra, quien había sido acusado de complicidad con los revolucionarios cuando éstos ocuparon el pueblo de Membiray pero finalmente resultó absuelto y se le restituyeron sus bienes. ${ }^{27}$ Peor suerte corrió fray Calixto Esquibias, quien quedó prisionero luego de enfrentar una causa por estar involucrado en la "revolución" del pueblo de Mizque y, como afirma el expediente, "resultó complicado por hechos positivos" por "delitos de infidencia al Rey". ${ }^{28}$

Un caso singular y que merece mayor atención es el seguido contra el abogado Manuel Eusebio Ruíz por su defensa de Don Pedro Fortun, quien había habilitado un pago al ejército liderado por Castelli. Ruíz afirmó que Fortun actuó guiado

...de los principios de una sana filosofía, y de los preceptos de nuestra religión Cristiana, siguiendo al Apóstol San Pablo en la Epístola trece a los Romanos, que dice: no hay potestad que no venga de Dios, y así todas las que hoy son ordenadas por Dios. Por tanto el que resiste a la Potestad, resiste a las órdenes de Dios, y que por eso es necesario estar obedientes a cualesquiera autoridades, no solo por temor de la fuerza, sino también por la conciencia. ${ }^{29}$

Luego Ruiz sostenía que los cristianos de los primeros siglos nunca pusieron "otra defensa que la paciencia, y el sufrimiento" ante la opresión de los emperadores romanos, "enemigos de la religión cristiana". Y finalizaba su exposición afirmando "Por esta máxima justa, y verdadera dimanada del Evangelio fue inducido mi representado para obedecer: Este solo testimonio cuando no hubieran otros, es suficiente para que (...) por haber obedecido no sea calificado por delincuente". ${ }^{30}$

\footnotetext{
${ }^{25}$ Archivo Nacional de Bolivia (ANB), Fondo Emancipación de la Audiencia de La Plata (EALP), Ficha 90. Autos criminales seguidos contra el doctor José Hermenegildo Quiroga, cura de la doctrina del Paredón, por delitos de infidencia. Potosí, 8 de julio de 1812 / La Plata, 16 de enero de 1813. Folio 1-1v.

${ }^{26}$ ANB, EALP, Ficha 88. Causa criminal seguida contra fray Juan de la Cruz Orozco, por las inteligencias que tuvo con los caudillos en el alzamiento de Mohosa. Mohosa, $1^{\circ}$ de julio de 1812 / La Plata, 24 de diciembre de 1812,. F. 6-7.

${ }^{27}$ ANB, EALP, Ficha 119. Sentencia pronunciada por la Audiencia de La Plata en la causa criminal seguida contra el presbítero José Andrés Salvatierra, por sospechas en su conducta cuando los insurgentes del Río de la Plata invadieron el pueblo de Membiray. La Plata 27 de noviembre de 1812. F. 1-2v

${ }^{28}$ ANB, EALP, Ficha 102. Expediente formado en virtud de la causa seguida contra fray Calixto Esquibias, involucrado en la revolución del partido de Mizque. La Plata, 24 de septiembre de 1812 / 15 de febrero de 1813. F. 2.

${ }^{29}$ ANB, EALP, Ficha 110. Expediente criminal seguido contra el abogado, por haber sentado en un escrito que la autoridad de Castelli fue legítima. La Plata, 11 de octubre de 1812 / La Plata, 21 de noviembre de 1812. F. 1.

${ }^{30}$ ANB, EALP, Ficha 110. Expediente criminal seguido contra el abogado... F. 1. Subrayado en el original.
} 
La estrategia de defensa resultó irritante para el fiscal quien presentó sus pareceres indicando que "la proposición de que Castelli y sus socios fueron potestades de las que habla el Apóstol, con obligación a obedecerlos de parte nuestra, y que Fortun se sometió porque el Evangelio nos lo manda es tan aventurada, sacrílega, y escandalosa". ${ }^{31} \mathrm{La}$ causa giró y se volvió netamente contra el letrado, quien fue acusado de defender la legitimidad del gobierno revolucionario y se defendió señalando justamente que "nunca ha pesado decir que la potestad del Insurgente Castelli fue legítima". ${ }^{32}$ Además cambió sus argumentos y esgrimió que Fortun había obedecido ante "el conocimiento que tenia, que de no obedecer, le resultaría el grave daño de perderse y perder su familia". ${ }^{33} \mathrm{De}$ todos modos, ya era tarde, fue acusado de manifestar ante un Magistrado del Rey que "Castelli y sus secuaces fueron potestades a quienes se debió obedecer como derivados de Dios", lo que implicaba "grandísimo crimen", siendo entonces "culpable y digno de castigo con una pena extraordinaria que sirva de escarmiento público". ${ }^{34}$ Finalmente, luego de numerosas instancias posteriores, Ruiz fue liberado bajo fianza y se le prohibió ejercer su profesión por seis meses.

El problema radicaba en la utilización del postulado que indicaba la necesaria obediencia que se debía seguir a las autoridades para indicar que no era un delito haber colaborado con los revolucionarios. En su estudio sobre los sucesos acaecidos en Nueva Granada en una coyuntura compleja similar a la que estamos analizando, Juan Bosco Amores Carredano señala que la obediencia y la lealtad generaban un vínculo religiosomoral con el soberano de modo que la rebeldía era justamente un delito de "«lesa majestad civil» equiparable al de apostasía y herejía” (Amores Carredano, 2011b: 148). Atribuir ese poder soberano a Castelli generó en las autoridades una vehemencia inusitada puesto que invertía sus discursos de poder y aumentaba las posibilidades de asignar al gobierno de Castelli características que pudieran contemplarse como positiva, principalmente con sustentos religiosos. Esta vehemencia es similar a la desplegada por los líderes del ejército realista, con Goyeneche a la cabeza, quienes, como veremos más adelante, no escatimaron en demonizar a su enemigo.

\section{La retirada del ejército, herejía y saqueos}

Si bien ya tomamos en consideración ciertas acusaciones contra los capellanes que acompañaron al ejército, sin dudas más trascendentes fueron las que se realizaron sobre la oficialidad del Ejército. La reprobación de determinadas conductas religiosas se extendió con notable velocidad y parece haber sido relevante para tornar fallida, en estos términos, la intervención del Ejército sobre el Alto Perú.

En primer lugar encontramos acusaciones que no parecen ser menores sobre el propio Castelli. Su ingreso a la ciudad de La Paz en abril de 1811 fue nada menos que el miércoles santo, con un despliegue de la banda militar que parecía desconocer el

\footnotetext{
${ }^{31}$ ANB, EALP, Ficha 110. Expediente criminal seguido contra el abogado... F. 1v.

${ }^{32}$ ANB, EALP, Ficha 110. Expediente criminal seguido contra el abogado... F. 5v.

${ }^{33}$ ANB, EALP, Ficha 110. Expediente criminal seguido contra el abogado... F. 6.

${ }^{34}$ ANB, EALP, Ficha 110. Expediente criminal seguido contra el abogado... F. 9.
} 
Gómez. Conflictos religiosos y adhesiones políticas en la guerra revolucionaria. La retirada del ejército...

recogimiento que ameritaba la fecha. En ese sentido, los festejos realizados en su honor fueron catalogados como impiadosos. En la misma dirección, Andrés García Camba, miembro de las tropas realistas, afirma en sus memorias que en su menosprecio de Goyeneche, Castelli había señalado que lo vencerían "aunque Dios no quisiera" (García Camba, 1846: 56). Estos dichos, ciertos o no, tuvieron eco en la época y constituyeron una de las preguntas que conformaron el interrogatorio que se le siguió a los testigos en la Causa del Desaguadero en la que se juzgó el accionar de Castelli y el ejército. ${ }^{35}$

Continuando con esta recapitulación, encontramos en la causa judicial sobre la derrota del Desaguadero respuestas sugerentes que indican un consenso al señalar una controvertida acción cometida por ciertos oficiales en Chuquisaca. Al parecer los oficiales al salir de un baile tomaron una cruz de un postigo del cementerio de la Iglesia de San Francisco y la arrastraron por la calle. El teniente de dragones ligeros Sebastián de la Mella indica en su testimonio judicial que los oficiales en cuestión "agarraron una cruz y la despreciaron". ${ }^{36}$ En la misma causa algunos declarantes manifiestan desconocer el hecho mientras que otros se refieren al episodio desligándose pero acordando en lo sustancial. ${ }^{37}$ Este suceso cobró notoriedad y es recuperado por la historiografía como un momento clave en la posterior consideración del ejército como impío que impulsaron sus adversarios. Pablo Ortemberg lo menciona como un episodio de gran resonancia (Ortemberg, 2012: 29) y Roberto Di Stefano lo relata marcando un estado de ebriedad en los oficiales y lo ubica como una práctica anticlerical (Di Stefano, 2000: 206-207 y Di Stefano, 2010: 84-85). ${ }^{38}$ A nuestro entender no se puede considerar este episodio sin tener presente las diferencias que subyacen en las prácticas religiosas en los distintos espacios del antiguo Virreinato del Río de la Plata. En este sentido es interesante destacar que la conducta atribuida a los oficiales puede considerarse no tanto como un ataque a la religión sino más bien un ataque a ciertas prácticas religiosas, justamente en defensa de las formas devocionales que ellos interpretan como válidas y, en este caso, como las únicas posibles. Así, esta diferencia sustancial entre prácticas religiosas enfrenta por un lado una religiosidad local con tonos barrocos y por otro una lectura más ilustrada

\footnotetext{
35 "Interrogatorio por el cual serían examinados los testigos" Buenos Aires, 14 de febrero de 1812. En "Causa del Desaguadero", ob. cit. p. 11777-8. En el mismo sentido y con la distancia que merece, encontramos que Frías afirma que se acusó a Monteagudo de proclamar en Laja un sermón, dirigiéndose desde el púlpito disfrazado con atuendos religiosos, desde donde habría proclamado consignas sacrílegas.

36 "Causa del Desaguadero", ob. cit. pp. 11785.

${ }^{37}$ Véase otro testimonio, el del subteniente del regimiento de dragones, Gregorio Zeballos en idem. pp. 11785-7. Del sargento mayor del regimiento numero 2 José León Domínguez, el 24 de febrero de 1812. En Ídem, pp. 11793-6. Y las del padre Antonio Cuesta, quien detalla el hecho con mayor precisión el 18 de marzo de 1812. En Ídem, pp. 11820-3 Desaguadero", ob. cit. p. 11777-8. Cayetano Bruno ha intentado reparar la memoria de Castelli ante las acusaciones de impío que él presumía como deshonrosas en un capítulo de un singular libro dedicado a distintas figura. A pesar de que los fines que movilizaron su escrito estaban delineados con precisión antes de su trabajo hermenéutico, es valorable la utilización de las fuentes que realiza (Bruno, 1992).

${ }^{38}$ También Cayetano Bruno dio por verídico este acontecimiento sin analizarlo y con la mayor preocupación de exculpar a Castelli otorgándole la acción a los oficiales mencionados e incluso profundizando en el escarmiento que ciertos testigos atribuyen al líder del ejército sobre los presuntos autores del hecho. (Bruno, 1992: 20-21).
} 
que no podía ver en esas prácticas otra cosa que un exceso intolerable que como tal debía reprimirse. Abonando esta hipótesis, encontramos que el Capitán del regimiento número 6, Esteban Figueroa, fue consultado meses más tarde por las acusaciones que pesaban sobre el ejército en términos religiosos y afirmó

Que el único exceso que se notó en materia de religión fue el de una cruz que unos oficiales jóvenes del ejército echaron por tierra en Chuquisaca, y la arrastraron hasta la plaza, lo que sabido por el doctor Castelli, y entendido del disgusto general con que se había mirado en el pueblo esta conducta de los oficiales, llamó a todos en general y los reprendió ásperamente, expresándoles que el ejército no había ido a remediar abusos en asuntos de religión... ${ }^{39}$

La búsqueda de "remediar abusos" o "ilustrar" a los chuquisaqueños en el plano religioso no puede entonces ubicarse como una práctica contra la religión en general siguiendo los planteos de los enemigos del ejército comandado por Castelli. ${ }^{40}$ De todos modos, para la población local, es probable que sí haya constituido una impiedad sin más en la medida que posiblemente su religiosidad era pensada como universal y no como una forma de piedad determinada. A fin de cuentas, la intolerante medida de los oficiales no se ve atenuada en su significado por ser un intento correctivo sino que cobra mayor trascendencia aún en la medida que constituye un agravio más hacia las comunidades locales coadyuvando a las creencias que ubicaba al ejército revolucionario como un ejército invasor de ocupación..$^{41}$

Este breve repaso no hace más que añadir elementos que potenciaron la voluntad de Goyeneche de ubicar a los porteños como enemigos de la religión. Sin embargo, la voluntad de Goyeneche no explica por sí misma la notable resonancia que tuvo en el Alto Perú la creencia negativa sobre el Ejército Auxiliar. Sobre todo porque encontramos repetidas veces las mismas intenciones por parte de los líderes militares

\footnotetext{
39 "Causa del Desaguadero", ob. cit. pp. 11812.

${ }^{40} \mathrm{Al}$ respecto, Acevedo señala toda una serie de registros que denotan distintas desviaciones de los eclesiásticos en el Alto Perú y la coexistencia entre la feligresía de signos de elevada religiosidad junto a toda una pléyade de prácticas (Acevedo, 1992: 322 y ss)

${ }^{41}$ Tomamos estos conceptos de Raquel Gil Montero, quien ha estudiado con rigurosidad la coyuntura advirtiendo: "Aunque libertadores para algunos, en general la actuación de los rioplatenses fue percibida por la población local como la de un ejército de ocupación, desde el momento que se nombró como gobernadores nada menos que de Potosí y Chuquisaca a dos porteños y además no se incorporó a los mandos militares a ninguno de los oficiales altoperuanos que no sólo demostraron fidelidad sino también capacidad en las luchas, posibilidad de acción conjunta y recursos en hombres y armas -sin hablar de aquellos vinculados a la manutención de las tropas" (Gil Montero, 2006: 96). Interpretar a este suceso como una confrontación de prácticas religiosas antes que un ataque a la religión no invalida la caracterización de anticlerical que le atribuye Di Stefano, puesto que dentro de dicha caracterización están comprendidas múltiples prácticas y posiciones entre las que se incluyen las dos interpretaciones de este episodio. (Di Stefano, 2012: 9 y ss.)
} 
de la época. Es decir, son repetidos los intentos de demonizar al enemigo y atribuir un carácter sacro a la propia causa. En la coyuntura específica, cabe traer a cuenta que el carácter antireligioso de la causa revolucionaria ya había sido denunciado por Vicente Nieto en septiembre de 1810, antes de los hechos anteriormente narrados, es decir previamente al arribo de la expedición que terminaría con su vida. Nieto comunicó la llegada desde España de noticias provechosas para su causa, marcando además que la plaza de Montevideo

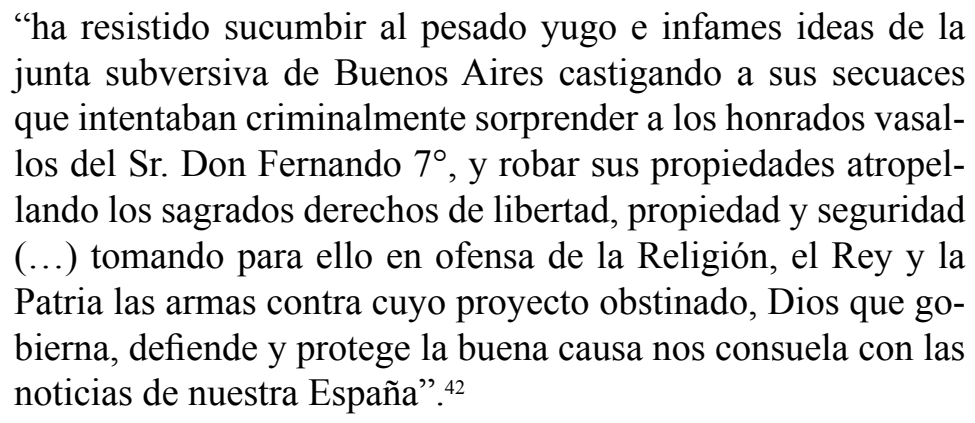

En el mismo sentido, es sugerente que con la ocupación de los porteños, las comunidades locales catalogaron a los realistas con apelativos ofensivos, acusándolos de moros y sarracenos, un insulto corriente que no dejaba de inquietar a los realistas. Así, encontramos que luego de retirado el ejército revolucionario de Chuquisaca, se estableció un nuevo gobernador, el Teniente Coronel Don Mariano Campero de Ugarte, quien emitió el 24 de septiembre de 1811 un Bando de buen gobierno en el que se mostraba "lleno de la mayor satisfacción al ver las atenciones y aprecios que ha debido al vecindario la tropa del Rey" y manifestaba que su gobierno tenía por objeto

tranquilizar y reunir los ánimos agitados de esta Capital y Provincia por la pérfida conducta del Gobierno del Río de la Plata y su infame tropa, que al abrigo de las lisonjeras ideas de libertad, felicidad y Patria, solo han dejado por escarmiento la dolorosa experiencia de llorar la violación de nuestros templos, ultrajes de nuestra Santa Religión y derechos Sagrados del Rey, los particulares de cada vecino, y el horror de los desórdenes y la anarquía no queda que desear para la más completa satisfacción del mismo gobierno y vecindario, sino el ver olvidado entre sus habitantes, los insociales ridículos apodos de Sarracenos y Moros que encuentra tan gradado [ilegible] el trato vulgar y que recordando ideas de enemistad (...) exponen

\footnotetext{
${ }^{42}$ Vicente Nieto, Bando público $1^{\circ}$ de septiembre de 1810. En Colección Mayo. Patrocinada por la comisión Nacional de Homenaje a la Revolución de Mayo en su 150 aniversario. 1810-1960. Tomo IV: Castelli.
} 
a invertir la buena armonía que debe conservarse sin distinción entre unos mismos vasallos sagrado objeto sobre que vigila este gobierno. ${ }^{43}$

Este documento ilustra la preocupación de los nuevos ocupantes de Chuquisaca ante la carga nominativa de los epítetos sarraceno y moro reproducidos por los chuquisaquenses. Sin embargo, nos parece más relevante la asociación inmediata entre las acusaciones de saqueo y ultrajes a la Santa Religión en la medida que nos llevan a postular una indisociable vinculación que articula las experiencias negativas que dejó la retirada del ejército derrotado con los epítetos y las representaciones que se le atribuyen. La extensión de la demonización de los rioplatenses en el Alto Perú no puede dejar de asociarse a una creencia generalizada que tenía como sustentación inequívoca las atrocidades que la tropa generó en desbandada.

La enorme magnitud de los desmanes fue sin dudas un elemento clave para la dispersión de las creencias que empezaron a recaer sobre el ejército y sobre el propio Castelli, generando que las comunidades altoperuanas no dudaran en ubicarlos como enemigos tornándose más permeables a los discursos que daban cuenta de las herejías de los saqueadores. En este sentido, el ayudante mayor Antonio Villata afirmó "la tropa dispersa cometió por donde pasaba toda especie de excesos, robando, violentando casas y aun matando a los que trataban de defender sus propiedades". Lo mismo señalan los capitanes Eustaquio Moldes y Jacobo García. ${ }^{44}$ Por su parte, Paz describe el repliegue como caótico y signado por una serie de "horrorosos combates" individuales o en grupo con las comunidades locales: “...el paisanaje y los indios por un lado, y los soldados que habían roto el freno de la obediencia por otro; los unos, por defender sus personas y propiedades; los otros, por invadirlas, los que hasta cierto punto eran disculpables, pues no marchando en cuerpo, no habiendo distribuciones regulares para satisfacer sus necesidades, habían de pedir o quitar, y ya se deja entender el camino que esto abría a los abusos" (Paz, 2000: 27).

En este punto es necesario traer a cuenta que no había una diferencia clara entre delito y pecado en el imaginario jurídico de la época, de forma tal que ciertos atropellos o acciones entendidas como injustas podían ser catalogado en sí mismas como un acto que se alejaba de las prácticas religiosas regladas (Clavero, 1990; Tomás y Valiente, 1969: 219 y ss.). La apropiación directa de recursos fue el mayor perjuicio que sufrieron las comunidades locales conformando un claro ataque a la reproducción de la vida cotidiana de los altoperuanos. De todos modos, no fue el único elemento de

${ }^{43}$ ANB, EALP, Ficha 55. Bando de buen gobierno de Mariano Campero de Ugarte La Plata, 24 de septiembre de 1811.

${ }^{44}$ Véanse las declaraciones del ayudante mayor don Antonio Villata. Buenos Aires 9 de diciembre de 1811. En "Causa del Desaguadero", ob. cit. pp. 11575-7. Las del Capitán don José Eustaquio Moldes. Buenos Aires 9 de diciembre de 1811. En "Causa del Desaguadero", ob. cit. pp. 11578-81. Las del capitán don Jacobo García. 10 de diciembre de 1811. En "Causa del Desaguadero", ob. cit. pp. 11581-3. Las del Capitán don Domingo Albariño. Buenos Aires 10 de diciembre de 1811.pp. 11583-6. García señala que los excesos cometidos por la tropa se debieron a la "obligada de la suma miseria en que marchaban". 
Gómez. Conflictos religiosos y adhesiones políticas en la guerra revolucionaria. La retirada del ejército...

disputa. Así hallamos que en la retirada, el ejército intentó detener la marcha en distintos puntos poblados con escaso éxito debido a la hostilidad que generaban los abusos de la oficialidad y la tropa. No es extraño encontrar entonces dos motines urbanos que merecen un trabajo de análisis aparte dada la tradición de resistencia que ciertas ciudades altoperuanas tenían frente a los ejércitos foráneos tal como lo ha demostrado Sergio Serulnikov (Serulnikov, 2009). Sólo nos interesa aquí mencionar que en Oruro y en Potosí los líderes y la tropa que conformaba lo que quedaba del Ejército Auxiliar debieron huir a paso redoblado ante el levantamiento local. En Potosí, el enfrentamiento fue de una envergadura considerable, y se contaron más de 150 muertes (Serulnikov, 2013). Los testimonios indican que el desencadenante de semejante tragedia habría sido un intento de abuso sexual de un soldado que fue repelido por el esposo de la víctima. ${ }^{45}$ De este modo, encontramos que las afrentas sobre el honor suponen un aditamento significativo para tener en cuenta a la hora de relevar el lugar que pasaron a ocupar los porteños en el imaginario altoperuano. ${ }^{46}$

¿Era entonces un problema de fe lo que impulsó a la catalogación de ejército impío que recayó sobre la expedición enviada desde Buenos Aires? Desde al Alto Perú, Tomás de Anchorena afirmaba en una carta a su hermano Mariano Nicolás "Lo que a mí más me desconsuela es el odio tan manifiesto de que se han poseído todas estas gentes contra nosotros. Ellas no desconocen la santidad y justicia de la causa que hemos proclamado, pero maldicen la conducta de nuestras tropas, culpando sobremanera a los oficiales y jefes. Yo creo que esta desgracia ha sido un castigo manifiesto de los innumerables delitos que se han cometido, y que nos servirá de freno para moderar nuestra conducta". ${ }^{47}$ Estas sugerentes palabras presentan un panorama diferente, otorgando mayor trascendencia a las conductas abusivas que venimos desarrollando. De todos modos, aún cuando las palabras de Anchorena no parecen ser totalmente desacertadas, nos parece que no dan cuenta de la influencia y el peso sustancial que tenía la creencia extendida sobre la impiedad del ejército.

Conjugando los atropellos materiales con las prácticas que serían acusadas directamente de sacrilegio encontramos además que las tropas en desbandada no dudaron en saquear parroquias e iglesias. Un auto del arzobispo Benito María Moxo Francoli, fechado en 5 de agosto de 1811, afirmaba que la "sangrienta acción del Desaguadero" acababa "de producir un trastorno bien grande en todos los pueblos. Uno de sus dolorosos efectos ha sido el que el inconsiderado atolondramiento de algunos derrotados que se retiraban apresuradamente, se haya atrevido a atentar las casas del Señor extrayendo sus alhajas y utensilios según se nos ha asegurado." ${ }^{88}$ Luego, sostenía que estos hechos

\footnotetext{
45 "Oficio del Presidente de Charcas Juan Martín de Pueyrredón a la Junta Gubernativa de Buenos Aires, informándole sobre los sucesos ocurridos en Potosí, en los días 5 y 6 de agosto, como consecuencia de la dispersión de las tropas que actuaron en Huaqui", en "Causa del Desaguadero", ob. cit. p. 11551 y ss.

${ }^{46}$ En un sugerente trabajo, Sergio Serulnikov ha llamado la atención sobre las problemáticas que incumben al honor como un campo tan poco estudiado como necesario para comprender con agudeza innumerables episodios de este período (Serulnikov, 2010).

${ }^{47}$ Carta del 10-8-1811. En AGN, Archivo Tomás M. de Anchorena, VII 313.

${ }^{48}$ Auto del Arzobispo Benito María de Moxo, La Plata, 5 de agosto de 1811. Archivo del Arzobispado de Sucre (AAS), Provisiones, licencias, nombramientos, №317.
} 
habían "consternado demasiado el espíritu de todas las personas piadosas" y anunciaba bajo la pena de excomunión mayor "que todos los que tuvieren, hubiesen comprado o supiesen en cuyo poder se hallen vasos sagrados o cosas pertenecientes a Iglesias, los restituyan y delaten a la mayor brevedad". Al parecer el auto del arzobispo no fue en vano puesto que antes de que pasen dos meses recibió una notificación de la Tesorería de La Plata convocándolo dado que se habían recogido "de los Soldados derrotados en la acción del Desaguadero cinco piezas pequeñas de Plata que pesan dos marcos tres onzas de Plata". En la misiva se agregaba que por su forma, las piezas parecían ser "de alguna Iglesia." 49

Estos saqueos tendrían un costo altísimo en la medida que el líder del ejército realista, José Manuel de Goyeneche potenciaría las escenificaciones que sacralizaban la causa del rey al mismo tiempo que ubicaban a los revolucionarios como sacrílegos. En sus memorias, Paz se detiene puntualmente a mencionar el ingreso de Goyeneche a la ciudad de Chuquisaca para describir el momento en el que el comandante en jefe realista solicitó a los sacerdotes locales que intervengan sobre el Palacio de la Presidencia donde se había albergado Castelli. A pedido de Goyeneche, el Palacio fue "purificado con exorcismos y otras preces de la iglesia; en consecuencia fue una especie de procesión en que los sacerdotes iban con hábitos sagrados, incensarios, hachas encendidas y abundante provisión de agua bendita. Sólo cuando después de una larga y edificante ceremonia se creyeron expelidos los malos espíritus, se dejó la casa habitable" (Paz, 2000: 54). ${ }^{50}$ El mismo Paz señala luego la habilidad de Goyeneche para potenciar el carácter religioso de su empresa inculcando en sus soldados "que los que morían eran reputados por mártires de la religión, y como tales, volaban directamente al cielo a recibir los premios eternos" (Paz, 2000: 53). ${ }^{51}$ Estas circunstancias, además de narradas, son evaluadas por el propio Paz, quien no duda en atribuir una trascendencia clave a la dimensión religiosa en la construcción de adhesiones cuando afirma "Además de política, era religiosa la guerra que se nos hacía, y no es necesario mucho esfuerzo de imaginación para comprender cuánto peso añadía esta última circunstancia a los ya muy graves obstáculos que teníamos que vencer" (Paz, 2000: 53)..$^{52}$

El retroceso de las tropas había dejado un tendal de abusos que generaron condiciones para que las acusaciones de Goyeneche encontraran interlocutores sumamente accesibles. Más allá de la exactitud de las acusaciones, nos interesa recuperar su verosimilitud en la medida que permite postular una extensión en el Alto Perú de

\footnotetext{
${ }^{49}$ Oficio de Miguel Cavellan y Tiburcio de Aldao de la Real Contaduría de La Plata al Arzobispo Benito María de Moxo, 13 de septiembre de 1811. AAS, Correspondencia.

${ }^{50}$ Seguidamente de estas menciones Paz emite un juicio problemático “¿Creía esto Goyeneche? No; el pueblo sí”.

${ }^{51}$ Incluso narra Paz que en el fusilamiento de un desertor, que fue capturado en momentos que intentaba pasarse al enemigo, el condenado exclamó causando conmoción general "Muero contento por mi religión y por mi rey".

${ }^{52}$ Igualmente hay que considerar que la práctica política de la primera expedición no fue estrictamente negativa y tal como lo ha demostrado María Luisa Soux, en el Alto Perú, durante estos tiempos "se organizaron de forma paralela grupos indígenas que, luego de la salida de los porteños se sublevaron en todo el altiplano" (Soux, 2008: 141).
} 
Gómez. Conflictos religiosos y adhesiones políticas en la guerra revolucionaria. La retirada del ejército...

creencias que encasillaban a los ejércitos invasores desde el sur como contrarios a dos de los pilares más frondosos de la articulación identitaria como eran el rey y la religión.

A fin de cuentas, cuando Belgrano se hizo cargo del ejército, el descrédito del mismo estaba sumamente extendido y el componente religioso de ese descrédito articulaba una identificación negativa considerablemente potente en tiempos donde, para buena parte de las poblaciones locales, no estaban claras las implicancias de optar por uno u otro bando en una guerra que irrumpía en su cotidianeidad generando mayores desgracias que beneficios. Estas problemáticas se pueden ver sintetizadas en un testimonio de Gregorio Aráoz de Lamadrid sobre la segunda avanzada sobre el Alto Perú, posterior a la batalla de Tucumán y previamente a la de Salta. Lamadrid refiere que en las inmediaciones de Salta se encontró con un sargento de las líneas enemigas y ante su interpelación, el sargento le indicó que se dirigía al pueblo a llevar unos fiambres y otras vituallas a su comandante y en cuanto al bando que ocupaba señaló el sargento: “Porteño! Ni Dios lo permita (...) Allí está mi guerrilla que es la que está peleando, lléveme Ud. Allá y verá que soy cristiano y no porteño". (Aráoz de Lamadrid, 1968: 23). Acto seguido Lamadrid, siempre según su propio relato, lo tomó prisionero y le quitó los fiambres que llevaba con los que se alimentó y luego convidó a su superior cuando le presentó el prisionero. La identificación como cristiano en oposición a porteño sintetiza la efectividad de la construcción identitaria que venimos repasando. Más aún, el final como prisionero y la sustracción de sus alforjas indudablemente afirmaron la cosmovisión del sargento a la hora de identificar a los porteños.

\section{Consideraciones finales}

Las implicancias de las desavenencias simbólicas que la primera incursión del Ejército Auxiliar del Perú tuvo en su paso por los distintos pueblos y ciudades de la región altoperuana son difíciles de evaluar. Recuperando nuestra pregunta inicial entendemos que estas desavenencias fueron cruciales para comprender los repetidos fracasos que posteriormente tuvieron los intentos de generar una adhesión masiva para la causa revolucionaria porteña. Sin embargo, las evidencias indican que un componente crucial para explicar la difusión de las acusaciones simbólicas sobre el ejército se encuentra en los atropellos que signaron la retirada hacia el sur luego de la derrota militar. Sin dudas, los saqueos y las afrentas que se desplegaron con variada intensidad posibilitaron la generación de una caracterización negativa de las conductas de los porteños que encontró en la religión un campo identificatorio tan asequible como efectivo. De este modo, entendemos que la dimensión religiosa no es ajena a las urgencias cotidianas y mundanas de forma tal que las representaciones simbólicas no sólo son elaboradas y creadas a partir de las vivencias de los ejércitos y las poblaciones que conviven con ellos, sino que además cobran fuerza o se vacían de significado justamente a partir de las experiencias de guerra que los sujetos protagonizan. En este punto nos distanciamos sutilmente de los planteos de Pablo Ortemberg, quien ha estudiado esta misma coyuntura poniendo mayor énfasis en el plano simbólico. Sin desatender completamente el componente material que contiene la disputa, Ortemberg ha privilegiado ahondar en 
la trama religiosa del conflicto indagando en los procederes de los cabecillas de ambos ejércitos. Sin dudas esta trama permite dar mayor coherencia a las distintas acciones que los líderes desplegaron en el plano religioso (Ortemberg, 2012). Sin embargo, a nuestro entender es vital incorporar en el escenario de conflicto a la relación que los ejércitos van desarrollando con las comunidades locales para comprender la elaboración de determinados signos o el desarrollo de los rituales religiosos pero sobre todo para indagar en las implicancias y los sentidos que cobran magnitud a partir de las ideaciones simbólicas.

Ciertamente, la imposibilidad de avanzar hacia Lima por la ruta terrestre que defendían los altoperuanos se debe analizar atendiendo a múltiples elementos. De todos modos, no parece menor el plano simbólico que relevamos en este trabajo, sobre todo considerando la expresa dependencia de recursos de todo tipo que los ejércitos tenían de las comunidades locales sobre las que se desplazaban..$^{53}$ Manuel Belgrano desarrollaría una política activa al interior del ejército intentando revertir las acusaciones que revisamos en este trabajo y dando cuenta de la trascendencia que tenía la dimensión religiosa en la construcción de adhesiones políticas y militares. Al mismo tiempo no ahorraba en proclamar entre la tropa el respeto de las comunidades locales que atravesaba el ejército. Los resultados de las acciones de Belgrano parecen haber sido positivos en la conjugación de voluntades si tenemos en cuenta las victorias de Tucumán y Salta (Gómez, 2011). Sin embargo, con similar lógica encontramos sus límites en el despliegue sobre el Alto Perú con las derrotas de Vilcapugio y Ayohuma que terminaron de sellar el límite norte de expansión de las tropas enviadas desde Buenos Aires luego de la Revolución de Mayo.

\section{Referencias bibliográficas}

Acevedo, E. O. 1992. Las intendencias altoperuanas en el Virreinato del Río de la Plata. Buenos Aires, Academia Nacional de la Historia.

Albert-Llorca, M. 2005. "La Vierge mise à nu par ses chambrières", CLIO. Histoire, femmes et sociétés [En ligne], 2 | 1995, mis en ligne le 01 janvier 2005, consulté le 04 juin 2013. URL: http://clio.revues.org/494 ; DOI : 10.4000/clio.494.

Amores Carredano, J. B. 2011a. "Las independencias hispanoamericanas en su bicentenario: nuevos planteamientos, nuevos enfoques", en Saranyana, JosepIgnasi y Juan Bosco Amores Carredano, Politica y religión en la independencia de América hispana. Madrid, Biblioteca de Autores Cristianos Universidad de Navarra.

Amores Carredano, J. B. 2011b. “"Gobernar según justicia». Realistas y patriotas en Nueva Granada (1810-1816)”, en Saranyana, Josep-Ignasi y Juan Bosco Amores Carredano, Politica y religión en la independencia de América hispana. Madrid, Biblioteca de Autores Cristianos Universidad de Navarra.

Aráoz de Lamadrid, Gregorio. 1968. Memorias, Buenos Aires, Eudeba.

\footnotetext{
${ }^{53} \mathrm{~A} 1$ respecto es sugerente el análisis de Raúl Fradkin para el litoral rioplatense, donde ha señalado que la guerra "no dejó de adoptar la forma de una guerra de autodefensa local" (Fradkin, 2009: 19).
} 
Gómez. Conflictos religiosos y adhesiones políticas en la guerra revolucionaria. La retirada del ejército...

Ávila, A. 2004. "De las independencias a la modernidad: notas sobre un cambio historiográfico". En: Pani, E. y Salmerón, A. (Coords.), Conceptualizar lo que se ve. François-Xavier Guerra, historiador. Homenaje, México, Instituto de Investigaciones Dr. José María Luis Mora.

Ayrolo, V. 2009. «El sermón como instrumento de intermediación cultural. Sermones del federalismo cordobés, 1815-1852», Nuevo Mundo Mundos Nuevos [En ligne], Débats, mis en ligne le 13 novembre 2009, consulté le 29 avril 2014. URL: http:// nuevomundo.revues.org/57521; DOI: $10.4000 /$ nuevomundo.57521.

Barnosell, G. 2010. «La Guerra de la Independencia como guerra religiosa: el ejemplo de los sitios de Zaragoza y Gerona», Nuevo Mundo Mundos Nuevos [En ligne], Débats, mis en ligne le 18 mai 2010, consulté le 26 juin 2012. URL: http:// nuevomundo.revues.org/59671; DOI : 10.4000/nuevomundo.59671

Barral, M. E. 2007 a. "Lo religioso como dimensión de análisis en la historiografía social sobre Hispanoamérica en el período colonial" En Sociedad y Religión, N ${ }^{\mathrm{o}}$ 28-29.

Bourdieu, P. 2009. La eficacia simbólica. Religión y política. Buenos Aires, Biblos. Brunet, J. 1974. Una orden militar y sus capellanes castrenses en América, Separata de Estudios Madrid.

Bruno, C. 1954. La Virgen Generala - Estudio documental, Rosario, Ediciones Didascálica.

Bruno, C. 1972. Historia de la Iglesia en la Argentina, Buenos Aires, Editorial Don Bosco, Vol. 8.

Bruno, C. 1992. Creo en la vida eterna. El ocaso cristiano de los próceres, Rosario, Didascálica, Tomo 1.

Carman, J. y Álvarez Rodríguez, G. (Eds.) 2010. Huellas de la Revolución. Documentos escritos de la semana de mayo, Buenos Aires, Asociación Apoyo al Museo Histórico Nacional.

Chartier, R. 1992. El Mundo como Representación. Historia Cultural: entre práctica y representación, Barcelona, Editorial Gedisa.

Chiaramonte, J. C. 1991. "El mito de los orígenes en la historiografía latinoamericana". En Boletín de Historia Argentina y Americana Dr. Emilio Ravignani, $3^{\circ}$ serie, $\mathrm{N}^{\mathrm{o}}$ 2, Buenos Aires. Chiaramonte, J. C. 1997. "La formación de los Estados nacionales en Iberoamérica". En Boletín de Historia Argentina y Americana Dr. Emilio Ravignani, $3^{\circ}$ serie, № 15, Buenos Aires. Claverie, E. 2007. "La Vierge, le désordre, la critique". En Terrain [En ligne], 14 | 1990, mis en ligne le 17 juillet 2007, 01 octobre 2012. URL: http://terrain.revues.org/2971; DOI: 10.4000/ terrain. 2971.

Claverie, E. et Charuty, G. 2009. "La vierge en action”. En Terrain [En ligne], 44 | 2005, mis en ligne le 15 mars 2009, 14 octobre 2012. URL: http://terrain.revues. org/10012; DOI: 10.4000/terrain.10012.

Clavero, B. 1990. "Delito y pecado. Noción y escala de transgresiones". En Tomás y Valiente, F.; Clavero, B.; Bermejo, J. L.; Gacto, E.; Hespanha, A. M.; Alvarez Alonso, C., Sexo barroco y otras transgresiones premodernas, Madrid, Alianza Editorial. 
De Certeau, M. 2004. La cultura en plural, Buenos Aires, Nueva Visión.

De Certeau, M. 2006. La debilidad de creer, Buenos Aires, Katz Barpal Editores.

Demélas-Bohy, M. D. 1995. "La guerra religiosa como modelo". En François Xavier

Guerra, Las revoluciones hispánicas: independencias americanas y liberalismo español, Madrid, Editorial Complutense.

Demélas-Bohy, M. D. 2007. Nacimiento de la guerra de guerrilla: el diario de José Santos Vargas (1810-1825), La Paz, Plural-Lima, IFEA.

Di Meglio, G. 2007. "La guerra de independencia en la historiografía argentina". En

Manuel Chust y José Antonio Serrano, (eds.), Debates sobre las independencias iberoamericanas, Madrid, AHILA/IBEROAMERICANA/VERVUERT.

Di Stefano, R. 2004. El púlpito y la plaza, Buenos Aires, Siglo XXI.

Di Stefano, R. 2010. Ovejas negras. Historia de los anticlericales argentinos, Buenos Aires, Sudamericana.

Di Stefano, R y Zanatta, L. 2000. Historia de la Iglesia argentina desde la conquista hasta fines del siglo XX, Buenos Aires, Grijalbo.

Fradkin, R. 2009. "Guerra y sociedad. Los ejércitos, las milicias y los pueblos en el litoral", ponencia presentada en las Jornadas "Independencia, historia y memoria. Hacia una reflexión sobre los procesos revolucionarios en Iberoamérica”, San Miguel de Tucumán.

Fradkin, R. 2010. "Las formas de hacer la guerra en el litoral rioplatense". En: Bandieri,

S. (comp.), La historia económica y los procesos de independencia en la América hispana, Buenos Aires, AAHE/Prometeo.

Frías, B. 1971. Historia del General Martín Güemes y de la Provincia de Salta: o sea de la independencia argentina, Buenos Aires, Ediciones Depalma, Vol. 2.

García Camba, A. 1846. Memorias para la historia de las armas españolas en el Perú, Madrid, Sociedad Tipográfica de Hortelano y Compañía, Vol. 1.

García de Loydi, L. 1965. Los capellanes del Ejército: ensayo histórico, Buenos Aires, Comando en Jefe del Ejército. Dirección de Estudios Históricos.

Gil Montero, R. 2006. "Las guerras de independencia en los andes meridionales". En Memoria Americana, $\mathrm{N}^{\circ} 14$.

Gómez, F. 2011, "Religiosidad y movilización política en la guerra revolucionaria”. En XIII Jornadas Interescuelas Departamentos de Historia, Catamarca.

Gómez, F. 2013. "Guerra y movilización popular en tiempos revolucionarios. Una perspectiva desde la Batalla de Tucumán”. En Foros de Historia Política $N^{o} 1$, noviembre. URL: http://historiapolitica.com/sectpopulares/.

Halperín Donghi, T. 1978. "Militarización revolucionaria en Buenos Aires, 1806-1815". En Halperín Donghi, T. El ocaso del orden colonial en Hispanoamérica, Buenos Aires, Sudamericana.

Halperin Donghi, T. 1986 "Para un balance del estado actual de los estudios de historia latinoamericana”. En HISLA, Revista Latinoamericana de Historia Económica y Social, $\mathrm{N}^{0} 5$.

Herrero, Fabián. 2012. "La idea de independencia durante los días de la Revolución americana y de la Restauración europea. El difícil sermón patriótico de Francisco Castañeda en la Catedral de Buenos Aires”. En Iberoamericana, XII, 45. 
Gómez. Conflictos religiosos y adhesiones políticas en la guerra revolucionaria. La retirada del ejército...

Lempérère, A. 2003. "De la República corporativa a la Nación moderna. México (1821-1860)". En: Annino, A. y François, X. G. (coords.) Inventando la Nación, Iberoamérica siglo XIX, México, Fondo de Cultura Económica.

Lempérière, A. 2004. "Revolución, guerra civil, guerra de independencia en el mundo hispánico, 1808-1825". En Ayer, ㅇ 55.

Macchi, V. 2012. “Guerra y política en el Río de la Plata: el caso del Ejército Auxiliar del Perú (1810-1811)". En Anuario de la Escuela de Historia Virtual, № 3.

Mallimaci, F. 2013. Atlas de las creencias religiosas en Argentina, Buenos Aires, Biblos. Martínez de Sánchez, Ana María (autora), Karina Clissa (colab.). 2010. El valor de la palabra en sermones patrios ¿Libertad o independencia?, Universidad Nacional de Córdoba, Córdoba.

Morea, A. 2011. "E1 Proceso de profesionalización del Ejército Auxiliar del Perú durante las guerras de independencia". En Quinto sol No 15 (2).

Ortemberg, P. 2011. "El General Pezuela y la Virgen del Carmen: la trama religiosa de la guerra". En Joaquín de la Pezuela, Compendio de los sucesos ocurridos en el Ejército del Perú y sus provincias (1813-1816), Edición y estudios introductorios por Pablo Ortemberg y Natalia Sobrevilla Perea, Editorial Centro de Estudios Bicentenario, Santiago de Chile.

Ortemberg, P. 2012. "Las Vírgenes Generalas: acción guerrera y práctica religiosa en las campañas del Alto Perú y el Río de la Plata (1810-1818)". En Boletín de Historia Argentina y Americana Dr. Emilio Ravignani, $3^{\circ}$ serie, №. 35, Buenos Aires.

Palacio, E. 1967. Los diecisiete mercedarios de Mayo, Buenos Aires, Talleres Gráficos D. E. Taladriz.

Paz, J. M. 2000. Memorias póstumas de José María Paz, Buenos Aires, Emecé.

Peire, J. 2000. El taller de los espejos. Iglesia e Imaginario 1767-1815. Claridad, Buenos Aires.

Picciuolo, J. L. 2013. "La Asistencia Espiritual en las Fuerzas Armadas”. En AA. VV. Guerra de la independencia. Una nueva visión. Buenos Aires, Emecé.

Raffo de la Reta, J. C. 1948. Historia de Juan Martín de Pueyrredón, Buenos Aires, Espasa-Calpe Argentina, S. A.

Ramallo, J. M. 1966. “La Guerra religiosa en el Alto Perú (1811-1813)”. En: Academia Nacional de la Historia, Cuarto Congreso Internacional de Historia de América, Buenos Aires.

Rabinovich, A. 2011. "El fenómeno de la deserción en las guerras de la revolución e independencia del Río de la Plata. Elementos cuantitativos y cualitativos para un análisis. 1810-1829”. En: Estudios interdisciplinarios de América latina y el Caribe, Tel Aviv, Vol. 22.

Rabinovich, A. 2013. Ser Soldados En La Guerra De La Independencia, Buenos Aires, Sudamericana.

Ruiz Santana, C. 1941. Los capellanes castrenses de los ejércitos argentinos, Inst. Arg. de Cultura Histórica, Carmen de las Flores.

Serulnikov, S. 2009. "Motines urbanos contra el ejército regular español. La Plata, 1782 y 1785”. En: Mata, S. y Bragoni, B. (Comp.) Entre la Colonia y la República: 
Insurgencias, rebeliones y cultura politica en América del Sur, Buenos Aires, Prometeo Libros.

Serulnikov, S. 2010. "Los actores de la revolución y el orden social". En Boletín de Historia Argentina y Americana Dr. Emilio Ravignani, $3^{\circ}$ serie, $N^{\circ} 33$, Buenos Aires.

Serulnikov, S. 2013. "Nuevas formas de hacer política: los sectores plebeyos urbanos y la debacle de la sociedad de Indias en el Alto Perú". En Raúl Fradkin y Gabriel Di Meglio (eds.), Hacer política. Ensayos sobre la participación popular rioplatense en el siglo XIX, Buenos Aires, Prometeo.

Soux, M. L. 2008. "Los caudillos insurgentes de la región de Oruro: entre la sublevación indígena y el sistema de guerrillas". En Beatríz Bragoni y Sara Mata, (comps.), Entre la Colonia y la República: Insurgencias, rebeliones y cultura política en América del Sur, Buenos Aires, Prometeo.

Tomás y Valiente, F. 1969. El Derecho Penal de la Monarquía Absoluta (Siglos XVI, XVII y XVIII), Madrid, Tecnos. Valda Martínez, E. 1989. Potosí durante la independencia de Charcas, 1810-1817, Potosí, Bolivia, Editorial Universitaria "Tomás Frías".

Wasserman, F. 2011. Juan José Castelli. De súbdito de la corona a líder revolucionario, Buenos Aires, Edhasa. 